\title{
Presence of Bereitschaftspotential preceding psychogenic myoclonus: clinical application of jerk-locked back averaging
}

\author{
K Terada, A Ikeda, P C Van Ness, T Nagamine, R Kaji, J Kimura, H Shibasaki
}

Department of Brain Pathophysiology

K Terada

A Ikeda

T Nagamine

H Shibasaki

Department of

Neurology

R Kaji

J Kimura

Kyoto University

School of Medicine,

Kyoto, Japan

Department of

Neurology, Cleveland

Clinic Foundation,

Cleveland, OH, USA

P C Van Ness

Correspondence to:

Dr Kiyohito Terada,

Department of Brain

Pathophysiology, Kyoto

University School of

University School of

Kawaramachi 54, Sakyo-ku,

Kyoto City, 606-01, Japan.

Received 14 November

1994 and in revised form

18 January 1995.

Accepted 17 February 1995

\begin{abstract}
The method of jerk-locked back averaging was applied to six patients with clinically diagnosed psychogenic myoclonus. Five patients had a slow negative EEG shift corresponding to Bereitschaftspotential at the central region starting 0.7 to $2 \cdot 1$ seconds before the onset of the myoclonic jerk. One patient had no potential preceding the myoclonic jerk, whereas a small negative potential preceded the voluntary movement mimicking the jerk. The demonstration of Bereitschaftspotential before an apparently involuntary myoclonic jerk helps the clinical diagnosis of psychogenic myoclonus, although the absence of Bereitschaftspotential does not necessarily indicate that the movement is involuntary. Jerk-locked back averaging is clinically useful as a specific laboratory examination in this condition.
\end{abstract}

\section{$(\Im$ Neurol Neurosurg Psychiatry 1995;58:745-747)}

Keywords: psychogenic myoclonus; Bereitschaftspotential; jerk-locked back averaging

Myoclonus is defined as sudden, quick, shock like, single or repetitive involuntary movements without loss of consciousness. ${ }^{1}$ Recently, Monday and Jankovic introduced the term "psychogenic myoclonus" to expand the definition of myoclonus from just invol- untary to the so called voluntary movements. ${ }^{2}$ They proposed the criteria of psychogenic myoclonus, but no objective laboratory finding was proposed. Jerk-locked back averaging, which is a back averaging technique of EEGs time locked to the EMG onset of jerks, is used for detecting the cortical spike preceding the jerks of cortical origin. ${ }^{3}$ Jerk-locked back averaging, when applied by using a long time constant and a wide analysis window, may detect Bereitschaftspotential if the movements are mediated by voluntary mechanisms, but not before involuntary or passive movements. ${ }^{4-7}$ In this study, jerk-locked back averaging was assessed in six patients with psychogenic myoclonus.

\section{Patients and methods}

We studied six patients, four men and two women (age range 20 to 65 years), presenting with apparently involuntary jerks (table). Jerks were seen in the bilateral limbs in patients 1 and 2 , in the neck in patients 3 and 5 , and in the trunk in patients 4 and 6 . The jerks in all six patients were consistent with "psychogenic myoclonus" according to the criteria proposed by Monday and Jankovic. ${ }^{2}$ All patients except patient 6 could stop their jerks for a short time when requested to do so or when distracted. No patient or family had a history of neurological disorders. None had paroxysmal abnormality on EEG. All five patients in whom the somatosensory evoked potentials (SEPs) after electric stimulation of

Clinical and electrophysiological findings in six patients with "psychogenic myoclonus"

\begin{tabular}{|c|c|c|c|c|c|c|c|c|c|c|}
\hline \multirow[b]{2}{*}{$\begin{array}{l}\text { Patient } \\
\text { No } \\
\text { (age, sex) }\end{array}$} & \multirow[b]{2}{*}{$\begin{array}{l}\text { Duration } \\
\text { of } \\
\text { illness }\end{array}$} & \multirow[b]{2}{*}{$\begin{array}{l}\text { Affected } \\
\text { part }\end{array}$} & \multirow[b]{2}{*}{$\begin{array}{l}\text { Effect of } \\
\text { distraction }\end{array}$} & \multirow[b]{2}{*}{$\begin{array}{l}\text { Other } \\
\text { neurological } \\
\text { finding }\end{array}$} & \multirow[b]{2}{*}{$\begin{array}{l}\text { Psychiatric } \\
\text { history }\end{array}$} & \multirow[b]{2}{*}{$E E G$} & \multirow[b]{2}{*}{ SEPS } & \multirow[b]{2}{*}{ Muscle for $\mathcal{F} L A$} & \multicolumn{2}{|c|}{ Results of $\mathcal{F} L A$} \\
\hline & & & & & & & & & $\begin{array}{l}\text { Myoclonic } \\
\text { jerk }\end{array}$ & $\begin{array}{l}\text { Intended } \\
\text { jerk }\end{array}$ \\
\hline $1(22, F)$ & 2 weeks & $\begin{array}{l}\text { Bilateral } \\
\text { limbs }\end{array}$ & Present & None & None & $\mathbf{N}$ & $\mathbf{N}$ & L biceps brachii & "BP" & ND \\
\hline $2(20, F)$ & 5 months & $\begin{array}{l}\text { Bilateral } \\
\text { limbs }\end{array}$ & Present & Unstable gait & None & $\mathbf{N}$ & $\mathbf{N}$ & R brachioradialis & "BP" & ND \\
\hline $\begin{array}{l}3(21, M) \\
4(65, M)\end{array}$ & $\begin{array}{r}3 y \\
30 y\end{array}$ & $\begin{array}{l}\text { Neck } \\
\text { Trunk }\end{array}$ & $\begin{array}{l}\text { Present } \\
\text { Present }\end{array}$ & $\begin{array}{l}\text { None } \\
\text { Oral } \\
\text { dyskinesia }\end{array}$ & $\begin{array}{l}\text { None } \\
\text { Depression }\end{array}$ & $\begin{array}{l}\mathbf{N} \\
\mathbf{N}\end{array}$ & $\begin{array}{l}\mathrm{N} \\
\mathrm{ND}\end{array}$ & $\begin{array}{l}\mathrm{R} S C M \\
\mathrm{~L} \text { rectus } \\
\text { abdominis }\end{array}$ & $\begin{array}{l}\text { "BP" } \\
\text { "BP" }\end{array}$ & $\begin{array}{l}\text { ND } \\
\text { BP }\end{array}$ \\
\hline $5(25, M)$ & $6 y$ & Neck & Present & Blepharospasm & $\begin{array}{l}\text { Psychiatric } \\
\text { disorder }\end{array}$ & $\mathbf{N}$ & $\mathbf{N}$ & L SCM & “BP" & ND \\
\hline $6(33, M)$ & 10 months & Trunk & Absent & None & None & $\mathbf{N}$ & $\mathbf{N}$ & $\begin{array}{l}\mathbf{R} \text { rectus } \\
\text { abdominis }\end{array}$ & $\begin{array}{l}\text { No } \\
\text { potential }\end{array}$ & BP \\
\hline
\end{tabular}

$\mathrm{N}=$ normal; $\mathrm{ND}=$ not done; JL = jerk-locked back averaging; SCM = sternocleidomastoid muscle; "BP" = possible Bereitschaftspotential; $\mathrm{BP}=$ Bereitschaftspotential 
the median nerve at wrist were examined had SEPs of normal amplitude and latency.

For the recording of jerk-locked back averaging, the patients sat or were supine, and were told to keep quiet with their eyes either gently closed or open depending on the patient. The EEGs were recorded from cup electrodes fixed on the scalp at $\mathrm{Cz}, \mathrm{C} 3$, and C4 (International 10/20 System) with collodion. In patients $1,2,4$, and 5, EEGs were also recorded from $\mathrm{C} 1$ and $\mathrm{C} 2$. All electrodes were referenced to linked earlobe electrodes. An electrode for monitoring an electro-oculogram (EOG) was placed below the lateral canthus on either side referenced to an ipsilateral earlobe electrode. Impedance of all electrodes was kept less than $5 \mathrm{k} \Omega$. For recording EMG associated with jerks, a pair of surface electrodes were placed $3 \mathrm{~cm}$ apart on the skin overlying the most intensively jerking muscle for each patient.

A long time constant was adopted for the EEG and EOG recording (three seconds for patients $3,4,5$, and 6 , and five seconds for patients 1 and 2), and the high frequency filter was set to $100 \mathrm{~Hz}$. The time constant was set to 0.0075 seconds and the high frequency filter to $100 \mathrm{~Hz}$, for the EMG recording. Signals from the EMG were rectified in patients $3,4,5$, and 6 , and processed without rectification in patients 1 and 2 . A $60 \mathrm{~Hz}$ notch filter was used in all channels. Fifty to 160 spontaneous jerks were recorded for each patient. The signals from 2.4 seconds before to 1.2 seconds after the EMG onset were stored on a computer for subsequent off line analysis at a sampling rate of $333 \mathrm{~Hz}$ per channel. The EEGs were averaged time locked to the EMG onset by using a special computer program that was a modification of the method described by Barrett et al. ${ }^{8}$ The EEG samples were excluded from analysis if there were eye movements or other artifacts before the EMG onset, or if consecutive jerks were less than two seconds apart. Baseline for the amplitude measurements was determined by averaging the segment from $2 \cdot 1$ to $1 \cdot 5 \mathrm{sec}$ onds before the EMG onset for each channel. Calibration data were collected just before each experiment.

In patients 4 and 6, EEGs in association with voluntary movements were also recorded. The patients were told to repeat voluntary movements mimicking their own myoclonic jerks at a self paced rate of every several seconds. The EEGs, EMG, and EOG were recorded from the same electrodes and analysed in the same manner as for the jerks.

\section{Results}

All patients except for patient 6 showed slow negative EEG potentials preceding the EMG onset (table, figure). The potentials started $0 \cdot 7$ to $2 \cdot 1$ seconds before the EMG onset and were maximal at $\mathrm{Cz}$ in all five patients. Toward the EMG onset, this slow potential became steeper on the hemisphere contralateral to the jerk in patients 1 and 2 who had jerks in the upper limbs. In patients 3,4 , and

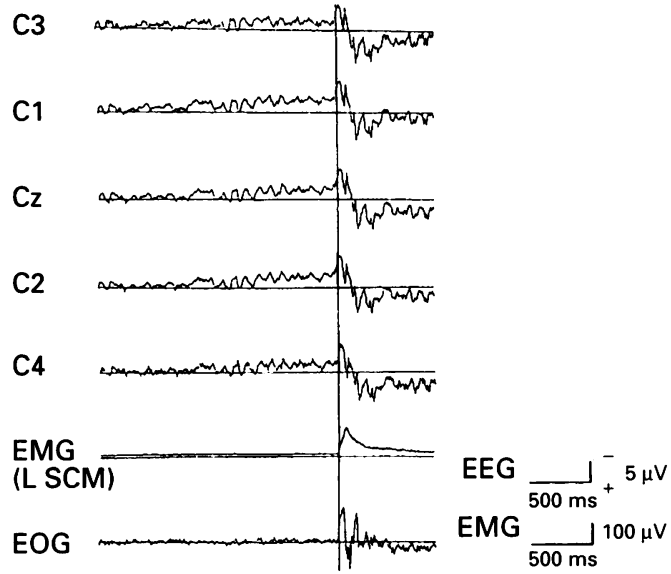

Averaged EEGs time locked to the myoclonic jerks recorded from the left sternocleidomastoid muscle (L SCM) in patient 5. A slow negative EEG shift starts from $1 \cdot 3$ seconds before the EMG onset, and is symmetric throughout.

5, who had jerks in the neck or trunk, this late steeper component was distributed symmetrically (figure).

In patient 4 , in whom EEGs in association with self paced voluntary movements mimicking the jerks were also recorded, Bereitschaftspotential started 1.5 seconds before the EMG onset and showed a similar distribution to the slow negative EEG shift seen in association with his myoclonic jerks. In patient 6, who did not have a slow EEG shift preceding the jerk, Bereitschaftspotential was present preceding the voluntary movements mimicking the myoclonic jerk. It started 0.7 seconds before the EMG onset and was maxi$\mathrm{mal}$ at $\mathrm{Cz}$.

\section{Discussion}

Monday and Jankovic described psychogenic myoclonus in 18 of their 212 patients with myoclonic jerks. ${ }^{2}$ They proposed the criteria for the diagnosis of psychogenic myoclonus, which consist of characteristic physical findings as well as history, positive placebo effects, and the absence of other underlying disorders that could cause myoclonus. Its laboratory diagnosis, however, was not taken into account.

It was originally reported that Bereitschaftspotential was absent before involuntary movements and present only before self paced voluntary movements. ${ }^{6}$ Recently, it was reported that jerk-locked back averaging was clinically useful to differentiate involuntary from voluntary movements, ${ }^{7}$ and that a slow negative EEG shift was present before psychogenic involuntary movement. ${ }^{9}$ Those studies suggested that slow negative EEG shifts may occur even before psychogenic involuntary movement, but not before purely involuntary movement.

As it is necessary to collect a sufficient number of jerks for making jerk-locked back averaging, there is an absolute limitation when applied to the patients with psychogenic myoclonus. When the jerks are too 
infrequent or too small to be picked up by the surface EMG, or when jerks occur too often (less than two seconds apart), this technique is not adequate. Therefore, this method is not always applicable to patients with psychogenic myoclonus and sometimes gives rise to noisy data because of an insufficient number of samples.

Among our six patients clinically consistent with psychogenic myoclonus, we could show the slow negative EEG shift preceding the myoclonic jerks in five patients. Therefore, it is most likely that the jerks in these patients were generated through the mechanisms common to those underlying the voluntary movement. Although there have been some reports of exceptional cases with involuntary movements that were preceded by the slow negative EEG shift (chorea-acanthocytosis, ${ }^{10}$ mirror movement ${ }^{11}{ }^{12}$ ), it is unlikely that the patients in the present study had those disorders.

The absence of a slow negative EEG shift preceding a psychogenic myoclonus and the presence of Bereitschaftspotential preceding the voluntary movement mimicking the jerk in the same patient, as seen in patient 6 , suggest that the generator mechanism of the jerk is different from that of the voluntary movement from the electrophysiological point of view. Because we occasionally encounter even normal subjects who show no or only small Bereitschaftspotential before voluntary movements, the conclusion as to whether those jerks are really involuntary or psychogenic in origin should be made with great caution. Nevertheless, demonstration of the slow EEG shift by jerk-locked back averaging may provide objective and supportive evidence for psychogenic myoclonus when it is clinically suggested.

This study was supported by a grant in aid for scientific research 06404031, a grant in aid for priority scientific research 06260225, and a grant in aid new programme 06NP0101 from the Japan Ministry of Education, Science, and Culture (for $\mathrm{HS}$ )

1 Fahn D, Marsden CD, Van Woert M. Definition and classification of myoclonus. In: Fahn S, Marsden CD Van Woert M, eds. Advances in neurology. Vol 43, myoclonus. New York: Raven Press, 1986:1-5.

2 Monday K, Jankovic J. Psychogenic myoclonus. Neurology 1993;43:349-52.

3 Shibasaki H, Kuroiwa Y. Electroencephalographic correlates of myoclonus. Electroencephalogr Clin Neurophysiol 1975;39:455-63.

4 Kornhuber $\mathrm{HH}$, Deecke L. Hirnpotentialänderungen bei Willkürbewegungen und passiven Bewegungen des Menschen: Bereitschaftspotential und reafferente Menschen: Bereitschaftspotential und

5 Shibasaki H, Barrett G, Halliday G, et al. Cortical potentials following voluntary and passive finger movements. Electroencephalogr Clin Neurophysiol 1980;50:201-13.

6 Obeso JA, Rothwell JC, Marsden CD. Simple tics in Gilles de la Tourette's syndrome are not prefaced by a normal premovement EEG potential. $\mathcal{f}$ Neurol Neurosurg Psychiatry 1981;44:735-8.

7 Trenkwalder C, Bucher SF, Oertel WH, et al. Bereitschaftspotential in idiopathic and symptomatic restless legs syndrome. Electroencephalogr Clin Neurophysiol 1993;89:95-103.

8 Barrett G, Shibasaki H, Nashigi R. A computer-assisted method for averaging movement-related cortical potentials with respect to EMG onset. Electroencephalogr Clin tials with respect to EMG onset

9 Toro C, Torres F. Electrophysiological correlates of a paroxysmal movement disorder. Ann Neurol 1986;20: 731-4.

10 Shibasaki H, Sakai T, Nishimura, et al. Involuntary movements in chorea-acanthocytosis: a comparison with Huntington's chorea. Ann Neurol 1982;12:311-4.

11 Shibasaki H, Nagae K. Mirror movement: application of movement-related cortical potentials. Ann Neurol 1984; 15:299-302.

12 Cohen LG, Meer J, Tarkka I, et al. Congenital mirror movements: abnormal organization of motor pathways in two patients. Brain 1991;114:381-403. 